\title{
A study of epidemiology of ectopic pregnancies in a tertiary care hospital of Mumbai, India
}

\author{
Deepali Kharat, Prajakta Goswami Giri*, Michelle Fonseca
}

\begin{abstract}
Department of Obstetrics and Gynecology, Lokmanya Tilak Municipal General Hospital and Medical College, Sion
\end{abstract} Mumbai, Maharashtra, India

Received: 25 June 2017

Accepted: 25 July 2017

\section{*Correspondence:}

Dr. Prajakta Goswami Giri,

E-mail: drpydeshmukh@gmail.com

Copyright: (c) the author(s), publisher and licensee Medip Academy. This is an open-access article distributed under the terms of the Creative Commons Attribution Non-Commercial License, which permits unrestricted non-commercial use, distribution, and reproduction in any medium, provided the original work is properly cited.

\section{ABSTRACT}

Background: Ectopic pregnancy is the result of a flaw in human reproductive physiology that allows the concept us to implant and mature outside the endometrial cavity which ultimately ends in the death of the fetus. Without timely diagnosis and treatment, ectopic pregnancy can become a life-threatening situation. Aim of the present study was to determine the incidence, clinical presentation, risk factors and immediate morbidity and mortality associated with ectopic pregnancy.

Methods: The study was conducted among 194 patients with ectopic pregnancy in a tertiary care hospital, over a period of two year. The following parameters: age, parity, gestational age, risk factors, clinical presentation, need for blood transfusion and findings on ultra-sonogram and morbidity associated with ectopic pregnancy were noted.

Results: The incidence of ectopic pregnancy was $0.76 \%$. Etiological factors observed were pelvic inflammatory disease $(13.9 \%)$, dilatation and curettage (8.8\%), infertility $(7.7 \%)$, previous abortions $(7.2 \%)$, intrauterine contraceptive device (3.6\%), previous ectopic pregnancy $(2.6 \%)$ and history of sterilization $(1.5 \%)$. The typical triad of amenorrhoea, pain in abdomen, and bleeding was observed in $76.5 \%$. Surgery by open method in the form of salpingectomy $(91.2 \%)$, salpingo-oophorectomy (5.7\%) and salpingo-oophectomy ovarian cystectomy $(4.1 \%)$ were the mainstay of management. Morbidity included anemia (24.2\%) and blood transfusion (87.6\%). No maternal mortality noted.

Conclusions: Early diagnosis, proper assessment of principal risk factors and timely intervention in the form of conventional or surgical treatment will help in reducing the morbidity and mortality associated with ectopic pregnancy.

Keywords: Ectopic pregnancy, Etiological factors, Salpingectomy, Salpingo-oophorectomy and ovarian cystectomy, Ultra-sonogram

\section{INTRODUCTION}

Ectopic pregnancy is one of the commonest acute abdominal emergencies a gynecologist has to meet in his day-to-day practice. It is an important cause of maternal morbidity and mortality especially in developing countries, where the majority of patients present late with rupture and hemodynamic compromise. ${ }^{1}$ However it not only threatens the life if not treated timely and effectively but also tells upon her fertility unavoidably by causing mutilation of an essential organ of reproduction, namely the fallopian tube with or without ovary and sometimes even the uterus. Many pathological conditions present a percentage of variables but only a few have greater disparity of symptoms, signs, opinions and reports as ectopic, which has made ectopic pregnancy both an interesting and challenging problem, which is at times so difficult to diagnose and manage. 
There are a few documented cases of viable pregnancy outside the uterus and tubes but, as a general rule, only an intrauterine pregnancy is viable. $95 \%$ of ectopic pregnancies occur in fallopian tubes, majority occur in the ampullary or isthmic portions of the fallopian tubes. ${ }^{2}$ About 2-3\% occurs as interstitial ectopic pregnancies (arising in the part of the tube which goes through the endometrial cavity). Other sites are cervical, fimbrial, ovarian and peritoneal sites, as well as previous caesarean section scars. An ectopic pregnancy may also co-exist with intrauterine pregnancy, this is called heterotopic pregnancy. It is a rare event, occurring in 1 in 30,000 pregnancies. $^{3}$

Ruptured ectopic pregnancy is the leading cause of maternal mortality in the first trimester and accounts for $10-15 \%$ of all maternal deaths. ${ }^{4}$ The early diagnosis and treatment of this condition over the past two decades have allowed a definitive medical management of unruptured ectopic pregnancy even before there were clinical symptoms in these high risk women. ${ }^{5,6}$ The reason for increasing incidence has not been fully elucidated, but the possible contribution of pelvic inflammatory disease (PID), ovulation inducing drugs, previous abdominalpelvic surgeries and intra-uterine contraceptive device use has been cited as contributing factors. ${ }^{7}$ The diagnosis of ectopic pregnancy has become more frequent during the last decades, but the incidence of ectopic pregnancy rupture has declined. This declined is due to quantitative human chorionic gonadotropin measurements, minimally invasive surgeries, and transvaginal ultrasonography (USG). ${ }^{8}$ Early diagnosis reduces the risk of tubal rupture and allows more conservative medical treatments to be employed. ${ }^{9}$

The present study was undertaken to provide a better understanding of ectopic gestation, its clinical presentation, and various risk factors associated with ectopic pregnancy.

\section{METHODS}

The current study was conducted in the Department of Obstetrics and Gynecology at Tertiary Care Hospital, Mumbai, (M.S.) for a period of 2 years after obtaining clearance from the Hospital Ethical Committee. Total 194 cases of ectopic pregnancy were diagnosed and recruited for the study after taking their consent for participation. All intrauterine pregnancies were excluded from the study. A detailed history and history suggestive of risk factors for ectopic pregnancy, menstrual and obstetric history were taken. General, systemic, abdominal, vaginal and perrectal examination was done. Data were recorded on pretested proforma. Information regarding the total number of deliveries in the study period, details of demographic characteristics, clinical symptoms and signs, diagnostic tools used, treatment, risk factors, site of ectopic pregnancy, genital infections, line of management as well as associated morbidity and mortality were obtained. All the surgical procedures were performed under spinal/general anesthesia. As majority of the patients had ruptured tubal gestation, a decision for removal of the tube i.e., unilateral salpingectomy was done by open laparotomy. Salpingectomy was combined with contralateral tubectomy in patients who did not wish to conceive. In cases with obvious pathological findings on the opposite side, the diseased adnexa were removed. Patients were followed up in the postoperative period with special attention to the development of fever abdominal pain, distension of the abdomen and wound sepsis. Patients were discharged with an advice to come for follow up after a week.

\section{Statistical analysis}

All the statistical operations were done through SPSS for Windows, Version 10.0. Contingency coefficient analysis (Cross tabs Procedure) and Chi-Square Test were used for statistical analysis.

\section{RESULTS}

Total numbers of deliveries during the study period were 25280 and we had 194 cases of ectopic pregnancy giving an incidence of 1:130 pregnancies. Among the 194 cases, 143 cases were ruptured ectopic and 51 are unruptured. Maximum incidence of tubal gestation occurred between the age group 26-30 years (62.9\%). $17.5 \%$ were primigravida whereas multiparas were $82.5 \%$. Most of the patients $(88.1 \%)$ cases were belonging to low socioeconomic status.

Table 1: Risk factors among ectopic pregnancy.

\begin{tabular}{|lll|}
\hline Risk factors & No. of cases & $\%$ \\
\hline No risk factor & 102 & 52.6 \\
\hline Pelvic inflammatory disease & 27 & 13.9 \\
\hline Dilatation and curettage & 17 & 8.8 \\
\hline Infertility & 15 & 7.7 \\
\hline Previous abortions & 14 & 7.2 \\
\hline IUCD $(\mathrm{Cu} 380 \mathrm{~A})$ & 7 & 3.6 \\
\hline Previous ectopic & 5 & 2.6 \\
pregnancies & 3 & 1.5 \\
\hline History of sterilization & 3 & 1.5 \\
\hline Oral contraceptives & 1 & 0.5 \\
\hline Appendicectomy & 194 & 100 \\
\hline Total & & \\
\hline
\end{tabular}

Chi-square $=62.471 ; \mathrm{P}<0.000$ (HS)

There were no risk factors identified in $52.6 \%$ of the cases. Infertility of more than 4 years was seen in 15 cases. $8.8 \%$ of the patients had undergone procedures such as dilatation and curettage previously. $1.5 \%$ and $3.6 \%$ of the cases used contraceptives in the form of oral contraceptive pills or IUCD respectively.

Twenty seven patients gave a history of pelvic inflammatory disease. Surgical procedures seen were appendicectomy in one patient and five patients had been operated previously for ectopic gestation (Table 1). 
Table 2: Site of ectopic pregnancy.

\begin{tabular}{|lll|}
\hline Site of ectopic pregnancy & No. of cases & $\%$ \\
\hline Interstitial & 66 & 34.0 \\
\hline Isthmal & 41 & 21.1 \\
\hline Ampullary & 87 & 44.9 \\
\hline
\end{tabular}

The general presenting complaints were abdominal pain $(92.8 \%)$, amenorrhea $(80.4 \%)$, abnormal vaginal bleeding $(61.9 \%)$ and $27.8 \%$ of the cases had other symptoms. The urinary pregnancy test was positive in $98.5 \%$ of the cases and positive predictive value of UPT was 0.93 . The commonest site of location of the ectopic pregnancy was in the ampulla of the fallopian tube. Other sites were interstitial followed by isthmal pregnancy as mentioned in (Table 2).

Right sided tubal pregnancy was present in $53.1 \%$ cases and left tubal involvement in $46.9 \%$ cases. Ruptured ectopic pregnancy was present in $68.5 \%$ cases on ultrasonography, $31.4 \%$ had unruptured ectopic but on laprotomy $73.7 \%$ cases diagnosed with ruptured ectopic pregnancy and $26.3 \%$ were unruptured. Approximately $75.8 \%$ of the cases had hemoglobin more than equal to 7 gm\% where as $24.2 \%$ of the cases had less than $7 \mathrm{gm} \%$. $87.6 \%$ patient required blood transfusion both intra operatively and post operatively. The most common surgery done was unilateral salpingectomy in $177(91.2 \%)$ cases, unilateral salpingo-oophorectomy in $11(5.7 \%)$ and unilateral salpingo-oophectomy ovarian cystectomy done in $8(4.1 \%)$ cases. 6 patients having maximum stay of hospital $>8$ days. There was no mortality observed in our study.

\section{DISCUSSION}

Incidence of ectopic pregnancy has increased over the last 20 years. This may be due to a number of factors: increased frequency of tubal infections, increase in the number of tubal operations and better facilities for diagnosis and treatment. However, the incidence of ectopic pregnancy in relation to intrauterine pregnancy in the present series was 1 in 130. Maximum number of ectopic pregnancies (i.e. $96.9 \%$ ) seen in patients between age group of 20 to 30 years and maximum incidence occurred between parity 2 and 4 ranging from parity $0-4$. This was consistent with different studies. ${ }^{10-12}$

The period of infertility varied from 4 to 6 years giving an incidence of $7.7 \%$ for infertility, it is stated that, ectopic pregnancy follows a period of infertility. Significant incidence of prolonged infertility and its causal relationship to ectopic pregnancy has been observed by several authors. ${ }^{10,13-15}$ However, the twenty seven patients gave a history of PID which contributes to $13.9 \%$. Literature shows that PID is an important factor predisposing to the development of ectopic pregnancy. According to other studies done by Rose et al, Banks M and Devi $S$ the incidence of PID as a risk factor is 4, 25 and $34.4 \%$ respectively. ${ }^{10,13,14}$ PID following gonococcal, chlamydial and other bacterial infection cause 3.3-6 fold increased risk of ectopic pregnancy. Many cases of chlamydia salpingitis are indolent cases that may go unrecognized causing tubal damage and subsequent tubal pregnancy. ${ }^{16}$

All these points bring forth the same fact into light that the recent change in sex life can cause pelvic inflammation and tubal damage in younger age groups causing more incidence of ectopic pregnancy in young, nulli or low parity women. There were six previous abdominal operations - appendicectomy and ectopic in the present series, $2.6 \%$ had previous tubal surgeries but the type of procedures they had undergone was not clear from their records. IUCD was used by only seven patients $(3.6 \%)$ and OCP was used by three patients $(1.5 \%)$. Throughout literature there are reports linking the use of various types of IUDs with the occurrence of ectopic pregnancy. The incidence of ectopic pregnancy was quoted in relation to the use of intrauterine devices by various authors. ${ }^{13,14}$

Manifestations of an unruptured tubal pregnancy are not characteristic. Correct diagnosis is rarely arrived at. Almost all the symptoms and signs produced by tubal pregnancy are caused by ultimate rupture of tubal wall or abortion with resultant hemorrhage into the peritoneal cavity. Hence, symptoms and signs of tubal pregnancy as described are nothing but the clinical description of tubal gestation which has been disturbed. In the present study, it was found that only a certain proportion of cases of tubal pregnancy presented a text book picture of amenorrhoea, bleeding per vaginum, fainting attacks, abdominal pain, tenderness and adnexal mass. No specific sign or symptom can be said to be pathognomonic of ectopic gestation, but combination of various findings may be lightly suggestive.

The clinical picture is dependent on several factors, the most important factor being the extent of time taken for disturbance to occur in ectopic gestation. The more extensive and rapid the disturbance, the clearer is the clinical picture. Hence, undisturbed ectopic gestation is likely to be missed in majority of the cases as the clinical features are vague. In present study classical history of amenorrhoea, pain abdomen and vaginal bleeding was present only in $76.5 \%$ cases. Acute pain in the lower abdomen was the most common presenting feature in $88.2 \%$ of the cases. It was present in $50 \%$ of cases of tubal rupture in the present series. Amenorrhoea was present in 156 cases $(80.4 \%)$.

The incidence was comparable to Rose et al. ${ }^{10}$ Oumachigui et al reported absence of amenorrhoea in $23 \%$ cases as against $24.1 \%$ in the present series. ${ }^{10}$ Vaginal bleeding of variable pattern was present in 120 cases $(62.9 \%)$. Amount of bleeding was scanty to moderate in most of the cases. Other symptoms were giddiness in 6 patients $(2.9 \%)$, retention of urine in 7 patients $(3.5 \%)$, loose stools in 11 patients $(5.6 \%)$ and nausea and vomiting in 6 patients $(2.9 \%)$. 
Ultrasonography reported $68.6 \%$ of them as ruptured, $31.4 \%$ of them as unruptured. ${ }^{10}$ Most of our patients were referred from outside with diagnosis of ruptured ectopic pregnancy. So, our treatment modality was mainly surgical. UPT test was simple test to see pregnancy there or not which was positive in 191 cases $(98.5 \%)$.

During the study, long hospital stay had an association with the condition of the patient like level of haemoglobin with need of blood transfusion this is because if the patient came with low haemoglobin level obviously will need blood transfusion of two units and above, in which will need more than three days of hospital stay. Parity had an association with long hospital stay with. Most of patients with abdominal pregnancy in this study stayed in the hospital seven days to three weeks.

Admission in ICU showed an association with long stay although statistically not significant. In this study multipara had relationship with long hospital stay than prime parity. This can be explained that, women who had carried pregnancy before are less worried with symptoms during early pregnancy compared to prime gravida, hence tend to seek medical care late and come with hypotension, shock and massive blood loss which needs transfusion more than two unit, and therefore stay longer in hospital. Other studies also reported sepsis, burst abdomen, haemoglobin level, and cardiac arrest during the laparotomy, as the reasons for patient to stay longer in Hospital. ${ }^{17,18}$ But in present study, there was no sepsis, burst abdomen or maternal mortality, all patients survived. This can be explained that patients received appropriate management in time when they reached at tertiary hospital despite of coming late with already ruptured ectopic pregnancies.

\section{CONCLUSION}

There is an increase in the incidence of ectopic pregnancy and a decrease in maternal mortality due to ectopic pregnancy, during the past two decades. The treatment modality also has evolved from radical to conservative surgery and even to medical and expectant management. But the paradox noted in this institution, is that even though the early diagnostic tools were available, we had to manage most of our patients as surgical emergencies, as they were brought late in the trial, with established diagnosis of ruptured ectopic pregnancy.

It is therefore important that all the physicians should be sensitive to the fact that in the reproductive age group any women presenting with pain in the lower abdomen, diagnosis of ectopic pregnancy should be entertained irrespective of the presence or absence of amenorrhoea, whether or not she has undergone sterilization.

\section{ACKNOWLEDGMENTS}

Authors would like to thank the Department of Obstetrics and Gynecology, Surgery, other staff of operation theatre and administration of Tertiary Care Hospital and Medical College, Mumbai, (M.S.), for permission to study and providing facility to carry out the work.

Funding: No funding sources

Conflict of interest: None declared

Ethical approval: The study was approved by the Institutional Ethics Committee

\section{REFERENCES}

1. Panti A, Ikechukwu NE, lukman OO, Yakubu A, Egondu SC, Tanko BA. Ectopic pregnancy at Usmanu Danfodiyo University Teaching Hospital Sokoto: a ten year review. Ann Niger Med. 2012;6(2):87-91.

2. Howkins and Bourne Shaw's Text book of Gynecology, 12th Ed. Publishers B.I. Churchil Livingstone Pvt Ltd.

3. Migda M, Migda M, Maleńczyk M, WenderOżegowska E. Heterotopic pregnancy in the absence of risk factors--diagnostics difficulties. Ginekol Pol. 2011;82(11):866-8.

4. Tenore J. Ectopic pregnancy. Am Fam Physician 2000;61(4):1080-8.

5. Stovall TG, Ling FW, Buster JE. Outpatient chemotherapy of unruptured ectopic pregnancy. Fertil Steril. 1989;51:435-8.

6. Stovall TG, Ling FW, Gray LA, Carson SA, Buster JE. Methotrexate treatment of unruptured ectopic pregnancy: A report of 100 cases. Obstet Gynecol 1991;77:749-53.

7. Pisarska MD, Carson SA, Buster JE. Ectopic pregnancy. Lancet. 1998;351:1115-20.

8. Timmerman D. Predictive models for the early diagnosis of ectopic pregnancy. Verh K Acad Geneeskd Belg. 2004;66:155-171.

9. Barnhart KT. Clinical practice. Ectopic pregnancy. N Engl J Med. 2009;361:379-87.

10. Jophy R, Thomas A, Mhaskar A. Ectopic pregnancy5 year experience. $\mathrm{J}$ Obstet Gynecol India. 2012;52(2):55-8.

11. Eastman NJ, Hellman LM. Williams Obstetrics. 12 ed. Appleton-Century-Crofts, New York, 1961:37395,437-50.

12. ICMR task free project. Multicentric case control study of ectopic pregnancy in India. J Obstet Gynaecol India. 1990;40:425.

13. Marchbanks PA, Annegers JF, Coulam CB, Strathy JH, Kurland LT. Risk factors for ectopic pregnancy: a population-based study. JAMA. 1988;259(12):18237.

14. Devi S. J Obstet Gynecol India. 2000;50(2):69-74.

15. Arora R, Rathore AM, Habebullah S, Oumachigui A. Ectopic pregnancy--changing trends. J Indian Med Assoc. 1998 Feb;96(2):53-4, 57.

16. Brunham RC, Binns B, McDowell J, Paraskevas M. Chlamydia trachomatis infection in women with ectopic pregnancy. Obstet Gynecol. 1986;67(3):7226. 
17. Dabota BY. Management and outcome of ectopic pregnancy in developing countries. Niger $\mathrm{J}$ Med. 2009;18(1):35-38.

18. Vyas PS. Epidermiology, diagnosis and management of ectopic pregnancy. LTMG Hospital, Sion, Mumbai. 1993-1998.
Cite this article as: Kharat D, Giri PG, Fonseca $M$ A study of epidemiology of ectopic pregnancies in a tertiary care hospital of Mumbai, India. Int J Reprod Contracept Obstet Gynecol 2017;6:3942-6. 